active learning in higher education

Copyright (C) 2005 The Higher Education Academy and SAGE Publications (London, Thousand Oaks, CA and New Delhi)

Vol 6(3): 256-268

DOI: $10.1177 / 1469787405057753$

ARTICLE

\section{Changing roles and competencies of academics}

\author{
SENGA BRIGGS The Robert Gordon University, Scotland
}

\begin{abstract}
This article presents the findings of a small study in a single school of a post-1992 university. The study considered the roles of the online academic and ascertained perceived competencies in these roles. The findings suggest gender differences in perceptions of the importance of online roles and gaps between roles and perceived competencies in these roles, suggesting some academics feel illequipped to meet online demands. The study indicates that appropriate learning and development programmes underpinned by relevant competency development are required. Notwithstanding, when asked to identify differences in roles and competencies in online and traditional environments, respondents indicated that their roles were similar in both environments. This suggested that a new 'generic' framework for academic roles and competencies was needed. The study then moved to develop a generic role model for use in all learning and teaching environments.
\end{abstract}

KEYWORDS: academics, competencies, online learning, roles

\title{
Introduction
}

Changes in higher education including changes in funding, competition amongst institutions, the increased use of technology and a shift to learnercentred education are combining to change the roles of both universities and academics. This article suggests that clarity in roles and the development of appropriate competency frameworks is essential for optimal performance in online roles. This challenges the accepted evolutionary nature of academic roles because it involves clearly defining the roles and competencies of academics rather than allowing them to evolve intuitively over time. The role of universities is becoming more complex, encompassing both the transfer of subject knowledge and the capability to apply skills in the context of specific fields and sectors (Zafeiriou et al., 2001). Academics are confronting the pressures of competing demands, balancing teaching with research or opting for one or the other and attempting to balance traditional workloads and pressures with the new pressure of online delivery. 
Web-based delivery has expanded learning environments and evidenced significant shifts from previous distance- and campus-based teaching, resulting in pedagogical changes, content and design changes and a rethinking of the role of technology and the role of the academic (Salmon, 2000). The emergence of large-scale degree programmes, offered by single mode distance education institutions, and the number of such programmes also focus attention on the changing role of the academic (Olcott, 1996). Academics themselves are concerned about the impact of online learning on student learning and on the role of the academic (Brown and Duguid, 1996). Thorsten (1996) suggests that funding changes are having an impact on roles and placing academics under mounting pressure to do more with less, increasing levels of stress. Salmon (2000) emphasizes the difference between the roles of the traditional and online academic whilst Jones and Schieman (1996) envision a new online model of 'the virtual professor' anchored to a particular institution. Huse and Cummings (1985) suggest lack of clarity about roles introduces role ambiguity and role conflict with significant impact on the achievement of personal and organizational goals, resulting in employee anxiety and dissatisfaction and lack of organizational effectiveness.

The aim of this study is thus to draw attention to the need for universities to address the changing roles and competencies of academics. To achieve this aim the study sought to consider online roles, establish perceived competencies in these roles and develop a generic role model for both the online and traditional learning and teaching environments. This article first reviews the literature on roles and competencies, then clarifies the study methodology and finally presents, analyses and discusses the results.

\section{Roles and competencies of academics}

Thomas and Biddle (1979) argue that role consists of the rights and duties associated with a post which are assigned to a post-holder. From a functional perspective roles are composed of behaviours that reflect responsibilities defined in job descriptions, such as designing and delivering learning and assessing learning outcomes. Changes in roles can lead to role overload, role ambiguity and role conflict (Rizzo et al., 1970). Role overload is used to describe situations where multiple roles are assumed to produce psychological distress. Role ambiguity arises from lack of clarity regarding duties, responsibilities and/or authority. Role conflict arises with the concurrent appearance of two or more incompatible expectations for behaviour (Biddle, 1986). Research has generally supported the hypothesis that role overload, role ambiguity and role conflict are directly linked to decreased job satisfaction, low performance and the propensity to leave 
organizations (Pearce, 1981). Indeed the literature suggests that lack of role clarity is the root cause of many organizational personnel problems and that role clarity gives a sense of belonging, a feeling of personal significance and a sense of continuity (Rizzo et al., 1974). Others suggest that defining the competencies which stem from roles not only reduces job dissatisfaction and low performance but is essential if organizations are to respond to change effectively (Johnson, 2000; Kelner, 2001).

Notwithstanding the terms, role and competency are often confused in the literature, but they are very different concepts. In particular, roles need to be broadly defined whilst competencies need to be specifically defined. Marrelli (1998) suggests that competencies are measurable capabilities that differentiate levels of performance in a job or role. Competencies flow from roles, and people who have the competencies required for a specific role typically perform better in that role than those who do not. This is no less true in higher education. Goodyear et al. (2001) suggest that a competent online teacher is a new and different role for academics and that the competencies required are different, e.g. IT expertise, information handling expertise, teaching and learning skills, time management and teambuilding skills. Some suggest that training and development in all aspects of online learning are required if optimal performance is to be achieved (Palloff and Pratt, 1999). However, relevant training and development programmes can only be identified once roles are clarified and underpinning competency frameworks developed.

The traditional role of the UK academic has evolved over time and, until recently, there was a clear view of what that role encompassed. Typically the academic was accredited as a subject expert, taught students and was involved in research. However, the online medium creates a unique environment which moves the time and place of the interaction and supports content in many formats. Thus engagement in online learning poses significant challenges for academics and universities. Role is at the heart of conflict and ambiguity in organizations and it is suggested that online roles and competencies are different from those required in the traditional learning environment. In line with literature on the subject, it is suggested here that organizations have to define roles and develop competency frameworks to understand and address the organizational and personal development challenges introduced by change.

Palloff and Pratt (1999) consider the transition to online learning means developing new approaches to education and new skills in delivery. Gustafson and Gibbs (2000) argue that teaching online requires strategies that develop new ways to guide students to discuss and reflect together. There are several classifications that seek to explain the roles of the online academic. Berge (1995) identifies four role categories: technical, 
managerial, pedagogical and social. This categorization illustrates that the online academic has a large range of roles (e.g. social, technical, discipline, etc.), each requiring the development of different types of competencies such as pedagogical and interpersonal skills. Lentell (2003) intimates that academics have to be knowledge experts, effective listeners and communicators as well as coaches, facilitators, mentors, problem solvers, designers, supporters and resource co-ordinators. A recent classification summed up much of the literature on roles and identified 11 clearly defined roles which appear in most classifications: technologist, manager, co-learner, designer, knowledge expert, researcher, facilitator, assessor, adviser-counsellor, etutor and mentor (Cornelius and Higgison, 2000). This classification will be used in this study.

\section{Research methodology}

A three-item questionnaire was designed to examine online roles and competencies. The first two questions measured perceptions of roles and competencies using the 11-role classification identified in Cornelius and Higgison (2000). Respondents were asked to identify which roles were essential and which were not and to measure their competencies in these roles against a 10-point scale. Each role was clearly defined (e.g. technologist: good operational understanding of software in use, reasonable keyboard skills and good knowledge of www and internet) to reduce potential ambiguity. The third question was open ended and examined perceptions of differences between roles and competencies in both the traditional and online environment.

The research was undertaken in the business school of a post-92 university. The target population was restricted to business school academics who were involved in both online and traditional learning. Approximately 105 academics work in the school and 59 were involved in both online and traditional learning at that time. Respondents were selected through a process of 'snowball sampling' (Vogt, 1999). This involved sending questionnaires to those known to be involved in both online and traditional delivery. Participants were asked to forward the questionnaire to other colleagues involved in both environments. The questionnaires were first issued in July 2003 and a representative sample was built over a six-week period. Fifty-two responses, 29 male and 23 female, were received; 65 per cent had been involved in online delivery for less than a year, 23 per cent for one to two years and 12 per cent for more than two years. In addition to exploring generic outcomes, the opportunity was taken to consider whether there might be gender differences. Fox (1990) suggests that males feel comfortable in a lecturing role and that lecturing is a demonstration of 
Table 1a Males - frequency of importance of online roles

\begin{tabular}{lcccccccccc}
\hline \multirow{2}{*}{ Role } & \multicolumn{1}{c}{ Scale $1-10$} & Not important & \multicolumn{3}{c}{ Essential) } \\
\cline { 2 - 11 } & 1 & 2 & 3 & 4 & 5 & 6 & 7 & 8 & 9 & 10 \\
\hline Technologist & 2 & 0 & 4 & 4 & 2 & 5 & 1 & 6 & 3 & 2 \\
Manager & 3 & 0 & 2 & 2 & 0 & 6 & 4 & 8 & 3 & 1 \\
Co-learner & 0 & 2 & 2 & 0 & 3 & 2 & 5 & 8 & 5 & 2 \\
Designer & 0 & 0 & 1 & 2 & 6 & 2 & 5 & 5 & 2 & 6 \\
e-tutor & 0 & 0 & 3 & 4 & 4 & 3 & 6 & 3 & 3 & 3 \\
Knowledge expert & 0 & 0 & 0 & 2 & 3 & 5 & 6 & 4 & 3 & 6 \\
Researcher & 0 & 0 & 2 & 1 & 5 & 4 & 3 & 6 & 6 & 2 \\
Facilitator & 0 & 0 & 0 & 0 & 1 & 2 & 5 & 7 & 7 & 7 \\
Assessor & 1 & 0 & 0 & 0 & 3 & 2 & 6 & 6 & 5 & 6 \\
Adviser/counsellor & 0 & 0 & 0 & 1 & 3 & 7 & 6 & 5 & 2 & 5 \\
Mentor & 0 & 0 & 0 & 1 & 3 & 5 & 5 & 6 & 4 & 5 \\
\hline
\end{tabular}

$(n=29)$

expertise and status. Conversely, females feel comfortable in a listening role and at ease sharing their expertise with others. This suggests that females might feel more comfortable in the online environment than their male counterparts. A hypothesis was developed, that is, do males and females respond in the same proportion to each of the roles? The Mann-Whitney test was used to test the findings.

\section{The results}

The results presented are from the three questions and reflect three related but distinct areas of the survey. Results are therefore presented separately for each question. The results for the first question, which asked respondents to score the roles in terms of their perceptions of whether these were essential or unimportant roles of the online academic, are illustrated in Tables $1 \mathrm{a}$ and $1 \mathrm{~b}$.

These tables demonstrate that the majority of respondents scored all the roles (except technologist) as important to essential (i.e. scale 6-10). Indeed most of the frequencies are skewed towards the medium to high end of the scales. The consistently medium to high scores for all these roles (given the large number of roles) is of particular note. These findings were then collapsed into a scale of low, medium and high importance which illustrated that 17 females saw both the facilitator and mentor roles of equal high importance, followed by adviser/counsellor (16) and assessor (15). Twentyone males saw the facilitator role as of high importance, followed by assessor 
Table $1 b$ Females - frequency of importance of online roles

\begin{tabular}{lcccccccccc}
\hline \multirow{2}{*}{ Role } & \multicolumn{8}{c}{ Scale } & $1-10$ & \multicolumn{3}{c}{ Not important } & \multicolumn{3}{c}{ Essential) } \\
\cline { 2 - 11 } & 1 & 2 & 3 & 4 & 5 & 6 & 7 & 8 & 9 & 10 \\
\hline Technologist & 2 & 0 & 3 & 3 & 1 & 4 & 2 & 3 & 3 & 2 \\
Manager & 2 & 1 & 1 & 1 & 1 & 0 & 4 & 7 & 3 & 3 \\
Co-learner & 0 & 2 & 0 & 1 & 1 & 2 & 6 & 6 & 4 & 1 \\
Designer & 0 & 0 & 1 & 2 & 3 & 4 & 6 & 4 & 2 & 1 \\
e-tutor & 0 & 0 & 2 & 3 & 2 & 6 & 4 & 3 & 2 & 1 \\
Knowledge expert & 0 & 0 & 0 & 2 & 1 & 2 & 6 & 5 & 3 & 4 \\
Researcher & 0 & 0 & 0 & 1 & 4 & 4 & 6 & 3 & 2 & 3 \\
Facilitator & 0 & 0 & 0 & 0 & 1 & 1 & 4 & 5 & 4 & 8 \\
Assessor & 0 & 0 & 0 & 0 & 1 & 2 & 5 & 4 & 6 & 5 \\
Adviser/counsellor & 0 & 0 & 0 & 0 & 1 & 1 & 5 & 4 & 6 & 6 \\
Mentor & 0 & 0 & 0 & 0 & 2 & 1 & 3 & 4 & 7 & 6 \\
\hline
\end{tabular}

$(n=23)$

(17), co-learner (15) and mentor (15). Both genders saw the technologist role as being of low importance (males (10) and females (8)), followed by the manager role (males (7) and females (5)) and the e-tutor role (males (7) and females (5)). The low scores for e-tutor are perhaps surprising.

The results for question two, which asked respondents to score their own competencies against the roles, are illustrated in Tables $2 \mathrm{a}$ and $2 \mathrm{~b}$. Of particular note is the fact that the frequencies are much more evenly spread across the scale than was the case for the scoring on roles. This is especially noticeable in the male responses. Collapsing the responses to low, medium and high competency, males scored themselves as having low competency in several roles: e-tutor (13), designer (12), technologist (11), adviser/counsellor (10), mentor (8) and co-learner (8). Males had scored the adviser/counsellor (28/29), mentor (28/29) and co-learner (25/29) roles as important to essential. Males scored themselves as having medium to high competency in the researcher (26), assessor (24), facilitator (22) and knowledge expert (22) roles.

Females scored themselves as having medium to high competence in the knowledge expert (23), researcher (23), facilitator (21) and adviser/counsellor (21) roles. These were all roles they had scored as important to essential. Ten female respondents scored themselves as having low competency in the designer role, eight as having low competency in the e-tutor role and seven as having low competency in the technologist role. The responses indicate not only differences and ambiguities between genders but within genders. 
Table 2a Males - frequency of competency in online roles

\begin{tabular}{|c|c|c|c|c|c|c|c|c|c|c|}
\hline \multirow[t]{2}{*}{ Role } & \multicolumn{10}{|c|}{ Score $1-10(1=$ Very poor competency $10=$ Expert $)$} \\
\hline & 1 & 2 & 3 & 4 & 5 & 6 & 7 & 8 & 9 & 10 \\
\hline Technologist & 3 & 0 & 3 & 5 & 6 & 5 & 5 & 1 & 1 & 0 \\
\hline Manager & 0 & 3 & 2 & 3 & 4 & 6 & 5 & 5 & 1 & 0 \\
\hline Co-learner & 0 & 3 & 3 & 2 & 6 & 5 & 5 & 3 & 0 & 2 \\
\hline Designer & 2 & 2 & 4 & 5 & 4 & 5 & 4 & 2 & 1 & 0 \\
\hline e-tutor & 2 & 2 & 4 & 5 & 4 & 5 & 4 & 2 & 1 & 0 \\
\hline Knowledge expert & 3 & 0 & 1 & 3 & 4 & 3 & 7 & 4 & 3 & 1 \\
\hline Researcher & 0 & 3 & 0 & 0 & 5 & 6 & 5 & 5 & 5 & 0 \\
\hline Facilitator & 0 & 3 & 2 & 2 & 3 & 5 & 8 & 3 & 2 & 1 \\
\hline Assessor & 0 & 2 & 1 & 2 & 6 & 4 & 5 & 3 & 4 & 2 \\
\hline Adviser/counsellor & 3 & 3 & 2 & 2 & 1 & 6 & 5 & 5 & 2 & 0 \\
\hline Mentor & 2 & 3 & 2 & 1 & 3 & 2 & 6 & 7 & 2 & 1 \\
\hline
\end{tabular}

$(n=29)$

Table $2 b$ Females - frequency of competency in online roles

\begin{tabular}{|c|c|c|c|c|c|c|c|c|c|c|}
\hline \multirow[t]{2}{*}{ Role } & \multicolumn{10}{|c|}{ Score $1-10(1=$ Very poor competency $10=$ Expert $)$} \\
\hline & 1 & 2 & 3 & 4 & 5 & 6 & 7 & 8 & 9 & 10 \\
\hline Technologist & 3 & 2 & 2 & 0 & 4 & 5 & 4 & 2 & 0 & 1 \\
\hline Manager & 2 & 1 & 1 & 2 & 3 & 8 & 4 & 1 & 1 & 0 \\
\hline Co-learner & 2 & 0 & 2 & 0 & 7 & 6 & 4 & 2 & 0 & 0 \\
\hline Designer & 0 & 2 & 4 & 4 & 2 & 5 & 4 & 1 & 0 & 1 \\
\hline e-tutor & 0 & 4 & 2 & 2 & 4 & 1 & 4 & 5 & 0 & 1 \\
\hline Knowledge expert & 0 & 0 & 0 & 0 & 6 & 6 & 3 & 2 & 6 & 0 \\
\hline Researcher & 0 & 0 & 0 & 0 & 6 & 1 & 6 & 5 & 5 & 0 \\
\hline Facilitator & 0 & 0 & 0 & 2 & 3 & 1 & 6 & 7 & 4 & 0 \\
\hline Assessor & 0 & 0 & 0 & 3 & 0 & 5 & 6 & 5 & 3 & 1 \\
\hline Adviser/counsellor & 1 & 1 & 0 & 0 & 3 & 4 & 4 & 4 & 5 & 1 \\
\hline Mentor & 2 & 0 & 0 & 3 & 2 & 3 & 4 & 5 & 3 & 1 \\
\hline
\end{tabular}

$(n=23)$

To identify statistical significance and examine the hypothesis of similar levels of responses between genders, Mann-Whitney tests for importance and competency (on a 10-point scale) were undertaken. The results, illustrated in Table 3, show that male scores are significantly lower at 5 per cent 
Table 3 Comparison of gender responses by Mann-Whitney test

\begin{tabular}{lcc}
\hline Role & Importance & Competence \\
\hline Technologist & $0.941 \mathrm{ML}$ & $0.689 \mathrm{ML}$ \\
Manager & $0.249 \mathrm{ML}$ & $0.587 \mathrm{MH}$ \\
Co-learner & $0.955 \mathrm{MH}$ & $0.829 \mathrm{MH}$ \\
Designer & $0.391 \mathrm{MH}$ & $0.737 \mathrm{ML}$ \\
e-tutor & $0.802 \mathrm{MH}$ & $0.343 \mathrm{ML}$ \\
Knowledge expert & $0.660 \mathrm{ML}$ & $0.322 \mathrm{ML}$ \\
Researcher & $0.970 \mathrm{MH}$ & $0.353 \mathrm{ML}$ \\
Facilitator & $0.616 \mathrm{ML}$ & $0.039 \mathrm{ML}$ \\
Assessor & $0.487 \mathrm{ML}$ & $0.271 \mathrm{ML}^{*}$ \\
Adviser/counsellor & $0.023 \mathrm{ML}^{* *}$ & $0.051 \mathrm{ML}^{* *}$ \\
Mentor & $0.080 \mathrm{ML}^{*}$ & $0.551 \mathrm{M}$ \\
\hline
\end{tabular}

(Cells contain Significance Level and 'Male Mean Rank Higher', MH, or 'Lower', ML)

significance level for adviser/counsellor in both importance and competency. Additionally, male scores are significantly lower at 5 per cent significance level for facilitator with respect to competency and male scores are significantly lower at 10 per cent significance level for mentor with respect to importance. This suggests that males and females do not respond in equal proportion to each of the roles.

Lastly, respondents were asked to identify the main differences between roles and competencies in the traditional and online environments. Responses indicated that it is the ongoing demands on the online academic which differentiate the online environment. Difficulties in managing time online were a recurrent theme and 54 per cent were concerned that online work could place the tutor on a '24/7 treadmill'. Respondents (69\%) indicated that training provision for online work was inadequate. Others suggested that lack of proper resource allocation led to 'robbing Peter to pay Paul'. Some respondents (40\%) noted that the online environment was adding 'more stress to an already stressed environment'.

In terms of competencies, respondents suggested the online academic must be expert and comfortable in the 'desk top' environment; competent in translating the spoken word into electronic form without loss of sense and meaning; able to energize discourse without the benefit of the 'heard' expression, tone or body language. Notwithstanding respondents (67\%) suggested that 10 of the 11 roles (technologist excepting) were common in both the traditional and online environments. This suggested that any review of roles should take account of roles in both environments. This study thus moved to identify a generic role model for use in both environments. A 


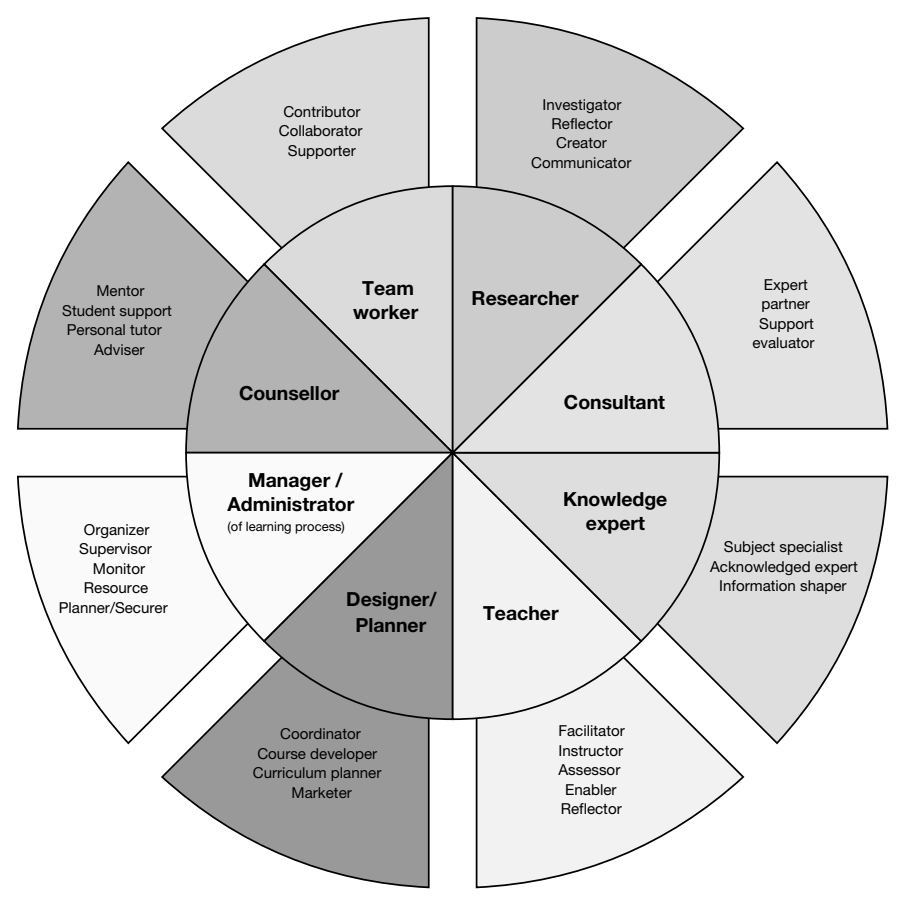

Figure 1 Generic role model

discussion group of 12 academics (experienced in both environments) was established, using a range of criteria including age, experience, gender and status. Discussions identified eight core roles (Figure 1, inner circle) that all academics undertake and eight peripheral roles (Figure 1, outer circle) which have a greater or lesser significance for individual academics. The eight core roles are all different, but interconnected and closely related, as some of the peripheral roles demonstrate.

\section{Discussion}

The responses indicate potential challenges with role overload, role ambiguity and role balance (e.g. time spent on each role) as well as differences between and within genders on the importance of individual roles. Differences can be expected given the broad range of student-teacher interactions online. The gender differences for both roles and competencies may in part relate to innate gender differences, but the differences between and within responses in the first two questions suggest a lack of clarity and some ambiguity regarding roles and their importance. The literature itself is confusing on the importance of individual roles. Ryan et al. (2000) 
suggest that the facilitator role is crucial, whilst Tammelin (2000) argues the manager role is critical. The high scoring for the range of roles, by both groups, suggests a perceived lack of role differentiation and potential role overload. Online learning represents discontinuity with previous practice, and this has the potential to cause role crisis. Without proper supports or interventions, role overload and role ambiguity can create the environment for a multitude of organizational and personnel problems. Clarity in roles gives a sense of belonging and a sense of continuity which should reduce some of the stress from role overload that online academics appear to be experiencing.

There were more significant differences between roles and perceived competencies in these roles. Academics rated some roles highly in terms of importance and then indicated their perceived low competencies in these roles (e.g. 10 females and 12 males scored themselves as having low competency in the designer role, whilst 26/29 males and 20/23 females scored this role of medium to high importance). All the role categorizations in the literature suggest that the online academic has a large range of roles to fulfil, each with the need to develop a wide range of different types of competencies. This alone can cause lack of clarity and ambiguity, especially in those new to the online environment with few existing skills in online learning. The use of competencies can, however, assist appropriate deployment of skills throughout learning and teaching provision. This might be achieved by using competencies to underpin the deployment of the academic resource to those areas of learning activity to which individuals can be best suited. In short, it has the potential to provide the basis for more effective resource deployment and a more motivated and challenged academic workforce.

With regard to the limitations of this study it should be noted that this was a restricted population of business school academics, although the small convenience sample was representative of the academic population in this section of the institution more generally. Whilst it is not possible to transfer the findings across the university or indeed across other universities, nonetheless this article seeks to raise awareness of the impact of role change on academics and universities and to consider whether universities should continue to allow roles and competencies to evolve or whether it is now appropriate to intervene to define roles and develop competency frameworks. Technology-enhanced learning has been a catalyst in accelerating learner-centred education. The change required by technology is demanding 'new' competencies. Information and communication technology requires a continuous process of development of online competencies, lifelong professional preparation and appropriate pedagogical training. Staff development programmes have to reflect the competencies 
required by individual academics, otherwise academics will 'do what they have always done' and neither they nor their students will benefit from the new media. This suggests a very personalized approach to staff development which would, in turn, be reflected in resource deployment and reduced staff development costs through greater focus on individual competency and performance related to institutional need.

The finding in the open question that academics undertake very similar roles in both environments is not that surprising given the broad nature of the concept of roles and moves to learner-centred education, with the result that certain roles (adviser/counsellor and facilitator) are becoming more prevalent in the traditional environment. Of course, the balance of roles will vary between and within universities, but in broad terms, as the generic model in Figure 1 suggests, most of the core roles will be common across universities and academics whatever the learning environment. This model can be used to provide a useful starting point for debate in this area.

\section{Conclusion}

Role is at the heart of many organizational problems and lack of clarity of role can lead to role ambiguity, role conflict and role overload. It is suggested that clarity of role(s) is essential for optimal performance in role(s) and for addressing wider issues of employee dissatisfaction, performance and retention. The results from the study reported in the article indicate that the multiple roles of online learning are placing more stress on already distressed academics at the institution used in the study. Future research is envisaged which will explore whether this is the case in other universities. The study also identifies differences between online roles and perceived competencies in these roles and suggests that there is confusion over the importance of roles. To this point the research is merely reiterating other research both on role theory and roles in online learning. However, it differs from other research in three ways, and this reinforces the need to qualify the findings from what is recognized as a small sample size.

First, whilst this survey specifically looked at online roles and competencies, nonetheless responses to the open question on differences between the online and traditional learning environments suggested that respondents perceived online and traditional roles to be similar in both environments and competencies to be the real differentiator between the online and traditional environments. Given the broad nature of the concept of roles and the move to learner-centred education, this is not surprising. Nonetheless, further research to validate this finding is required. Second, it 
identifies a generic role model for use in both environments and suggests the need to differentiate between core and peripheral roles. This makes sense given the multiple roles identified in most classifications and the confusion these cause. This model needs to be tested across the higher education sector but nonetheless provides a reasonable reference for future research.

Finally, the research suggests that plans for training and development can only be established after clear definition of roles and competencies. This challenges the accepted evolutionary nature of academic roles and involves clearly defining roles and competencies rather than allowing them simply to evolve over time. Although the roles of the online academic will continue to change as online learning environments become more prevalent and better understood, by clearly defining roles and competencies universities can perhaps control the impact of change and indeed shape change. Certainly, recent change in higher education would suggest that the resilience of academic institutions and roles may be insufficient in the face of radical and/or rapid change. Indeed, one might consider the potential for role clarity and disaggregation of academic roles to contribute to improved academic resource allocation modelling. In particular, it offers the potential to better align role and competency to need. This goes beyond the legitimate conclusions of this study but indicates the potential added value of role definition and competency development.

\section{References}

BERGE, Z. L. (1995) 'Facilitating Computer Conferencing: Recommendations from the Field’, Educational Technology 35(1): 22-30.

Biddle, B. J. (1986) 'Recent Developments in Role Theory', Annual Review of Sociology 12: 67-92.

BRown, J. S. \& DUGUid, P. (1996) 'Universities in the Digital Age', Change 28(4): 10 .

CORnelius, s. \& Higgison, c. (2000) 'The Tutor's Role. Online Tutoring e-Book'. Available at: http://otis.scotcit.ac.uk/onlinebook/otisT203.htm (accessed 8 November 2004).

FOX, T. (1990) The Social Uses of Writing: Politics and Pedagogy. Norwood, NJ: Ablex. GOOdyeAR, P., SAlmon, G., SPeCtor, J. M., Steeples, C. \& tickner, S. (2001)

'Competencies for Online Teaching: A Special Report', Educational Technology Research and Development 49(1): 65-72.

GUSTAFSON, P. \& GibBS, D. (2000) 'Guiding or Hiding? The Role of the Facilitator in Online Teaching and Learning', Teaching in Education 11(2): 20-30.

Huse, E. F. \& Cummings, T. G. (1985) Organization Development and Change, 3rd edn. St Paul, MN: West Publishing.

JOHnSON, M. (2000) New Roles for Educators. Available at: http://www.mff.org/ edtech/article.taf?_function=detail\&Content_uid $1=290 \& \# 62$ [accessed 20 November 2003].

JOnes, T. \& SChieman, E. (1996) 'Is Distance Education Ready for the Virtual 
Professor?' 12th Annual Canadian Association for Distance Education Conference, Monkton, New Brunswick, May: 22-5.

KeLner, s. (2001) 'A Few Thoughts on Executive Competency Convergence', Centre for Quality Management Journal 10(1): 67-72.

Lentell, H. (2003) 'The Importance of the Tutor in Open and Distance Learning', in A. Tait \& R. Mills (eds) Rethinking Learner Support in Distance Education, pp. 64-76. London: RoutledgeFalmer.

marrelli, A. F. (1998) 'An Introduction to Competency Analysis and Modelling', Performance Improvement 37(5): 8-17.

olcotT, D. J. (1996) 'Redefining Faculty Policies and Practices for the Knowledge Age', in D. E. Hanna \& Associates (eds) Higher Education in an Era of Digital Competition: Choices and Challenges, pp. 259-86. New York: Atwood Publishing.

PALlOfF, R.M. \& K. PRATT (1999) Building Learning Communities in Cyberspace: Effective Strategies for the On-line Classroom. San Francisco: Jossey-Bass.

PeARCE, J. L. (1981) 'Bringing Some Clarity to Role Ambiguity Research', Academy of Management Review 6(4): 655-64.

Rizzo, J. R., HOUSE, R. J. \& lirtzman, s. I. (1970) 'Role Conflict and

Ambiguity in Complex Organizations', Administrative Science Quarterly 15: 150-63.

RyAn, S., SCOTT, B., FREEMAN, H. \& PATEL, D. (2000) The Virtual University: The Internet and Resource Based Learning. London: Kogan Page Limited.

Salmon, G. (2000) E-moderating: The Key to Teaching and Learning Online. London: Kogan Page.

TAmmelin, M. (2000) 'Exploring the Roles of the Tutor in a Mixed Mode Course for University Students', in C. Higgison (ed.) Practitioners' Experiences in Online Tutoring: Case Studies from the OTiS e-Workshop. Available at: http://otis.scotcit.ac.uk/casestudy [accessed 22 November 2003].

THOMAS, E. \& BIDdle, B. (1979) 'The Nature and History of Role Theory', in

B. Biddle \& E. Thomas (eds) Role Theory: Concepts and Research. Huntingdon, NY: Robert

E. Krieger.

thorsten, E. (1996) 'Stress in Academe: What Bothers Professors?', Higher Education 31: 471-89.

vogt, W. P. (1999) Dictionary of Statistics and Methodology: A Non-technical Guide for the Social Sciences. London: SAGE.

Zafeiriou, G., Nunes, J. M. B. \& Ford, N. ( 2001) ‘Using Students' Perceptions of Participation in Collaborative Learning Activities in the Design of Online Learning Environments', Education for Information 19: 83-106.

\section{Biographical note}

SENGA BRIGGS is a Lecturer in Aberdeen Business School of the Robert Gordon University. She has been involved in online learning for four years and this has led to a research interest in the impact that changes in the use and practice of IT are having in higher education.

Address: Aberdeen Business School, The Robert Gordon University, Garthdee Road, Aberdeen AB10 7QE, UK. [email: s.briggs@rgu.ac.uk] 